\title{
Intraspecific variation in colony founding behavior and social organization in the honey ant Myrmecocystus mendax
}

\author{
T. H. Eriksson ${ }^{4}$ (1) $\cdot$ B. Hölldobler ${ }^{1}$ J. E. Taylor ${ }^{1,2} \cdot$ J. Gadau $^{1,3}$
}

Received: 8 December 2017 / Revised: 4 January 2019 / Accepted: 14 January 2019 / Published online: 23 January 2019

(C) International Union for the Study of Social Insects (IUSSI) 2019

\begin{abstract}
Persistent cooperation between unrelated reproductives occurs rarely in mature eusocial insect societies, and when present, is frequently geographically constrained. Here we present genetic and behavioral evidence showing that primary polygyny occurs in some, but not all populations of the honey ant Myrmecocystus mendax. Specifically, we found that all mature colonies sampled in a population in the Sierra Ancha Mountains of central Arizona (USA) were polygynous with a relatively high number of queens (average $=6.27$ ), while the majority of mature colonies sampled in the Chiricahua Mountains of southeastern Arizona were monogynous. Field and laboratory observations showed that Chiricahua foundresses are primarily haplometrotic, whereas Sierra Ancha foundresses can be either haplometrotic or facultatively pleometrotic. Nestmate relatedness of mature Sierra Ancha field colonies suggests that the reproductive individuals within these colonies are unrelated, consistent with primary polygyny. In the laboratory, Sierra Ancha foundresses cooperatively established incipient colonies without queen reduction, and colonies with multiple queens produced more minims and workers that may serve the role of repletes (honeypots) than haplometrotic colonies. This was in stark contrast to foundresses from the Chiricahua population, which showed strong aggression when forced to found colonies together in the laboratory. When brood raiding was experimentally induced between laboratory Sierra Ancha colonies, queens from colonies with more workers had a higher survival probability, although in some cases the competing colonies fused and queens from both colonies continued to reproduce. Fusion between incipient ant colonies is a rare phenomenon, but could contribute to the high frequency of polygyny and high queen number in mature colonies in the Sierra Ancha population.
\end{abstract}

Keywords Myrmecocystus $\cdot$ Honey ant $\cdot$ Pleometrosis $\cdot$ Primary polygyny $\cdot$ Colony fusion

Electronic supplementary material The online version of this article (https://doi.org/10.1007/s00040-019-00687-y) contains supplementary material, which is available to authorized users.

T. H. Eriksson

th3@asu.edu

1 School of Life Sciences, Arizona State University, Tempe, AZ 85287, USA

2 Center for Evolution and Medicine, Arizona State University, Tempe, AZ 85287, USA

3 Institute for Evolution and Biodiversity, Münster University, 47129 Münster, Germany

4 Present Address: School of Life Sciences, Arizona State University, Tempe, AZ 85287, USA

\section{Introduction}

Queen number is a key aspect of social organization in ant colonies and shows both inter- and intraspecific variation in natural populations (Rissing and Pollock 1988; Hölldobler and Wilson 1990; Bernasconi and Strassmann 1999; Overson et al. 2011; Helms and Cahan 2012). The simplest social organization of an ant colony consists of one foundress starting a new colony alone (haplometrosis) and monopolizing reproduction thereafter (monogyny). In a number of taxa, monogynous colonies can later adopt additional queens, thereby becoming secondarily polygynous. Less commonly, colonies are cooperatively established by multiple, usually unrelated foundresses (pleometrosis). Polygyny that arises from these associations is often short-lived (Tschinkel 1992; Bernasconi and Strassmann 1999). In most cases, all but one queen are subsequently culled following the emergence of the first workers, resulting in secondary monogyny 
(Hölldobler and Wilson 1990). However, when queen culling is absent, pleometrosis can lead to primary polygyny, a colony structure in which multiple, usually unrelated queens co-reproduce over time. Primary polygyny has been described for 22 species in the 15,000-16,000 recognized ant taxa, according to the literature search (AntWeb 2018; Bolton et al. 2007; Brian Haney per. com.). These species belong to 14 genera in five subfamilies, suggesting multiple evolutionary origins. Interestingly, primary polygyny is often not the only social structure within a given species but co-occurs with other social structures (e.g., secondary monogyny) at frequencies that vary geographically (Ross and Fletcher 1985; Overson et al. 2011; Helms and Helms Cahan 2012). This may indicate that primary polygyny is usually not an evolutionarily stable strategy and can only occur under restricted ecological conditions. So far, primary polygyny is best documented in the ant subfamily Myrmicinae (e.g., Mintzer and Vinson 1985; Ross and Fletcher 1985; Rissing et al. 1986; Hagen et al. 1988; Johnson 2004; Overson et al. 2011; Gotoh et al. 2017). Convincing evidence for primary polygyny in other subfamilies, including Formicinae, is not as common (e.g., Gadau et al. 1998; Schlüns et al. 2009; Hölldobler et al. 2011).

What are the possible proximate causes that promote the evolution of primary polygyny? One of the most likely factors is territory defense. Cooperative colony founding has been shown to increase the rate of brood production (Waloff 1957; Tschinkel and Howard 1983; Johnson 2004; Offenberg et al. 2012) and the total number of workers a colony produces (Bartz and Hölldobler 1982; Tschinkel and Howard 1983; Mintzer 1987; Sommer and Hölldobler 1992, 1995; Trunzer et al. 1998; Johnson 2004; Offenberg et al. 2012). These extra workers can boost colony survival by contributing to colony defense and resource acquisition (Bernasconi and Strassmann 1999). Species that found pleometrotically are often characterized by intense competition, both between founding colonies and between existing mature colonies. Neighboring colonies often engage in reciprocal brood raiding, during which competitors attack each other to steal brood and kill the queens, resulting in the death of the defeated colonies (Bartz and Hölldobler 1982; Rissing and Pollock 1988; Tschinkel 1992; Sommer and Hölldobler 1995; Adams and Tschinkel 1995). If such territorial pressures persist in a population, natural selection may favor pleometrosis over haplometrosis, potentially leading to primary polygyny. For example, in the honey ant Myrmecocystus mimicus, incipient and mature colonies with more workers were found to be more successful in ritualized territorial confrontations (tournaments) and brood raids (Hölldobler 1976; 1981; Bartz and Hölldobler 1982; Hölldobler et al. 2011; Kronauer et al. 2003). Indeed, there is evidence for both pleometrosis and unrelated matrilines in mature $M$. mimicus colonies (Hölldobler et al. 2011); however, the absence of queen culling, which is necessary for primary polygyny, has not yet been confirmed in this species.

In this article, we describe an investigation of social structure in another honey ant species, M. mendax. By combining genetic data and behavioral observations from both the field and the laboratory, we demonstrate striking differences in the distribution of colony founding strategy, queen number, degree of polyandry, and intracolonial relatedness between two allopatric populations in Arizona (USA). We also show that queens from the Sierra Ancha Mountains of central Arizona exhibit mutual tolerance, and that primary polygyny and colony fusion are present at this site. In contrast, most mature colonies in the Chiricahua Mountains of southeastern Arizona are monogynous, and foundresses and incipient colonies are highly aggressive to one another. We also conducted laboratory experiments to test how queen number influences the production of workers and repletes (workers that function as living storage vessels), and to determine how worker number affects queen survivorship in the context of intercolonial competition.

\section{Methods}

\section{Outline}

Our investigation had two main components. To explore the natural variation in social organization, we studied the sociogenetic structure of field colonies using microsatellite markers. We then performed a series of experiments with laboratory colonies started by foundresses collected from the field to investigate several behavioral traits that might be associated with the differences in social structure inferred from the genetic data. These experiments also enable us to better understand the costs and benefits associated with the different social strategies.

\section{Field sites}

Myrmecocystus mendax inhabits semiarid, mountainous regions throughout the southwestern United States and northern Mexico (Snelling 1976). In this study, we focused on two sites, one in the Sierra Ancha Mountains (abbreviated SIE henceforth; Gila County-AZ; 33.78475 , $-110.97103^{\circ}$ ), and the other in the Chiricahua Mountains (abbreviated CHI; Cochise County-AZ; 31.90046 , $-109.22757^{\circ}$ ). These sites are separated by $270 \mathrm{~km}$ of low elevation, arid environments not preferred by $M$. mendax. Species identification was confirmed by R.A. Johnson using the genus revision of Snelling (1976). Vouchers were deposited in the Social Insect Biodiversity Repository (SIBR) at Arizona State University (Tempe-AZ, USA). 
Queen number, mating frequency, and relatedness in field colonies

\section{Sampling}

To explore the variation in social organization of natural populations, we sampled workers from 11 mature field colonies in each population (Table 1) as they exited the nest or were found within $5 \mathrm{~cm}$ of the entrance without displaying any territorial behaviors (Fig. 1a, b), and directly stored in $70-95 \%$ ethanol. For colony SIE14, we also collected 21 winged females which were retrieved $10 \mathrm{~cm}$ below the nest

Table 1 Sample sizes for laboratory studies. The experiments and analyses are listed in the first column, followed by the corresponding populations in the second column and years in the third column

\begin{tabular}{lllll}
\hline Experiment/analysis & Population & Year & Sample size & Treatment group types \\
\hline Queen number, mating frequency, and & SIE & 2010 & 11 & Colonies \\
relatedness of in field colonies & CHI & 2010 & 11 & Colonies \\
Colony founding in the laboratory & SIE & 2013 & $17,18,24,8$ & Colonies started by 1, 2, 3, or 4 foundresses \\
& CHI & 2014 & 20,20 & Colonies started by 1 or 2 foundresses \\
& SIE & 2015 & $16,19,22$ & Colonies started with 1, 2, or 3 foundresses \\
Foundress survival & SIE & 2013 & $11,34,63,32$ & Queens in 1-, 2-, 3-, or 4-foundress colonies \\
& CHI & 2014 & 20,40 & Queens in 1- or 2-foundress colonies \\
& SIE & 2015 & $16,38,66$ & Queens in 1-, 2-, or 3-foundress colonies \\
Worker production & SIE & 2013 & $6,9,13,4$ & Colonies started by 1, 2, 3, or 4 queens \\
& CHI & 2014 & 25,12 & Colonies started by 1 or 2 queens \\
Replete production & SIE & 2015 & $12,17,18$ & Colonies started with 1, 2, or 3 queens \\
& SIE & 2015 & 12,32 (day 48) & Haplometrotic or pleometrotic colonies \\
Intercolonial competition & & & 15,34 (day 83) & \\
& CHI & 2014 & 9,2 & 1 queen-vs-1 queen or 1-vs-2 pairs \\
& SIE & 2015 & $4,6,7,3,6$ & 1-vs-1, 1-vs-2, 1-vs-3, 2-vs-2 or 2-vs-3 pairs
\end{tabular}

The fourth column shows the sample sizes with the units listed in the last column. For example: in the SIE colony founding experiment of 2013, there were 17 colonies each started by a single foundress

Fig. 1 a, b $M$. mendax workers engaging in lateral display with stilted legs and raised gasters, a typical territorial behavior of Myrmecocystus honey ants (Eriksson). c A developed $M$. mendax honeypot (Hölldobler). d M. mendax workers with filled and unfilled crops (Eriksson)

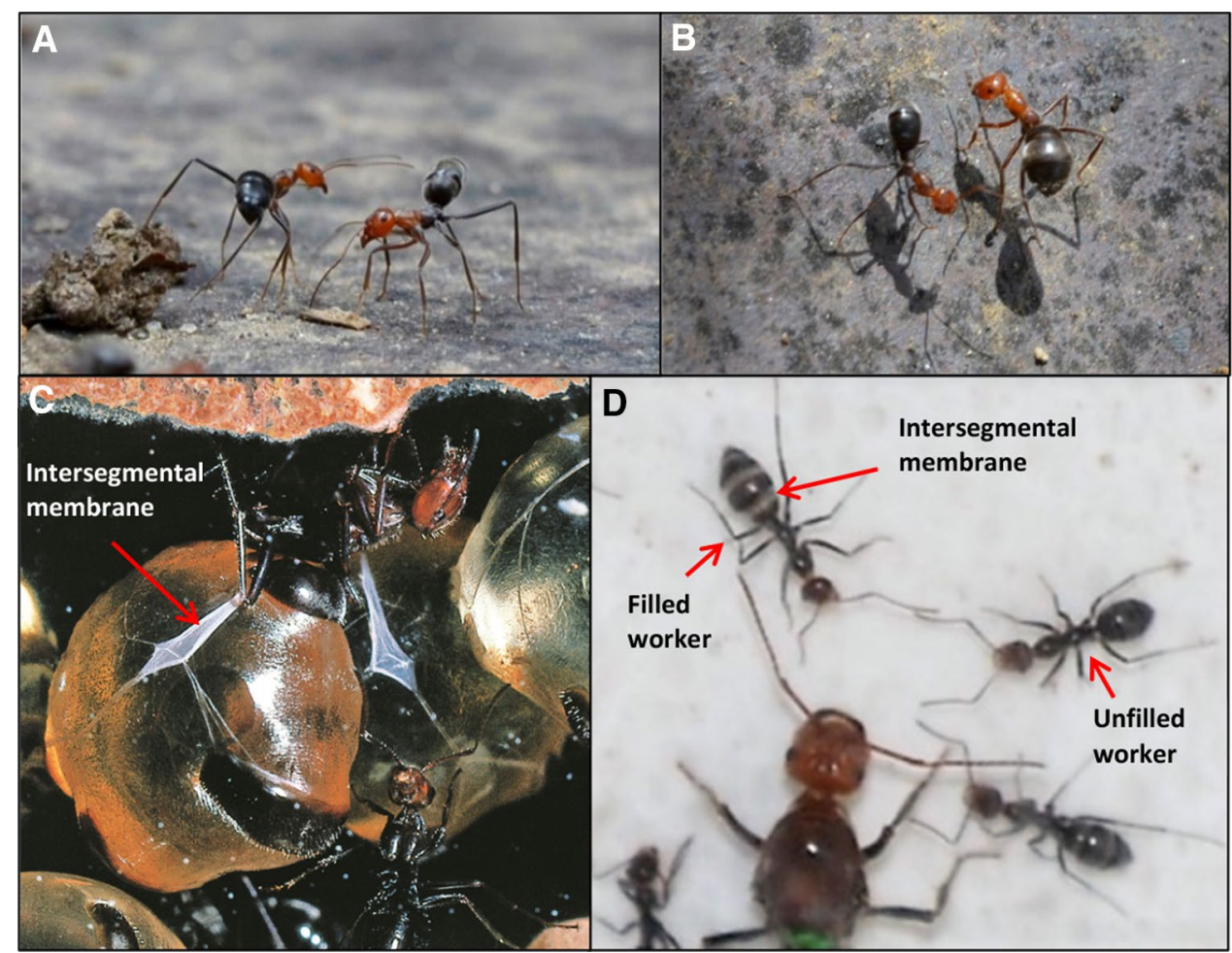


entrance. This allowed us to test whether there were multiple queens producing worker and sexual brood (functional polygyny). Colonies were determined to be mature by the presence of major workers, large nest craters, and winged sexuals.

\section{Genotyping}

Genomic DNA was isolated from samples using a Chelex ${ }^{\circledR}$ (Bio-Rad, Inc., Hercules, CA)—based method (Gadau 2009). Individuals were genotyped for four microsatellite markers: Mm3, Mm4, Mm5 (Kronauer and Gadau 2002), and FE17 (Gyllenstrand et al. 2002), with the exceptions of the SIE14 winged females and the colony fusion study (see below) where only the Mm markers were genotyped. PCR was performed using the following protocol: each $20 \mu \mathrm{l}$ reaction consisted of $13 \mu \mathrm{l}$ of ultrapure water, $4 \mu \mathrm{l}$ of $5 \times$ Colorless GoTaq Reaction Buffer (w/1.5 $\mathrm{mM} \mathrm{MgCl}_{2}$ ), $0.4 \mu \mathrm{l}$ of $10 \mathrm{mM}$ dNTP mix, $0.7 \mu \mathrm{l}$ of $10 \mathrm{mM}$ of each primer (one was fluorescently labelled), $0.2 \mu \mathrm{l}$ of Taq DNA Polymerase $(\sim 5$ $\mathrm{u} / \mu \mathrm{l})$, and $1 \mu \mathrm{l}$ of DNA template (concentration varied). Two thermal profiles were used, one for the $\mathrm{Mm}$ loci (denaturation: 2 min at $94^{\circ} \mathrm{C}$; elongation: 30 cycles each for $20 \mathrm{~s}$ at $94{ }^{\circ} \mathrm{C}, 30 \mathrm{~s}$ at $56^{\circ} \mathrm{C}$, and $1 \mathrm{~min}$ at $72{ }^{\circ} \mathrm{C}$; termination: $5 \mathrm{~min}$ at $72{ }^{\circ} \mathrm{C}$ ), and the other for FE17 (denaturation: 2 min at $94{ }^{\circ} \mathrm{C}$; elongation: 30 amplification cycles each for $20 \mathrm{~s}$ at $94{ }^{\circ} \mathrm{C}, 30 \mathrm{~s}$ at $51^{\circ} \mathrm{C}$, and $1 \mathrm{~min}$ at $72{ }^{\circ} \mathrm{C}$; termination: $5 \mathrm{~min}$ at $72{ }^{\circ} \mathrm{C}$ ). PCR products were analyzed on a 4300 DNA Analyzer (LI-COR, Inc., Lincoln, NE) and an ABI 3730 DNA Analyzer (Thermo Fisher Scientific). Alleles were scored using Saga ${ }^{\text {GT }}$ (LICOR) and Genemapper ${ }^{\circledR}$ (Thermo Fisher Scientific). Allele size, count, and heterozygosity are reported in Table 2. Genotyped specimens missing data at two or more loci were excluded from downstream analyses.

\section{Queen number and mating frequency analysis}

We inferred the number of reproducing queens and their mating frequencies (degree of polyandry) using COLONY

Table 2 Descriptions of microsatellite loci characteristics from this study

\begin{tabular}{llllll}
\hline Locus & Size range (bp) & $n$ & $A$ & $H_{\mathrm{o}}$ & $H_{\mathrm{e}}$ \\
\hline Mm3 & $133-203 / 137-209$ & $302 / 306$ & $21 / 34$ & $0.96 / 0.89$ & $0.92 / 0.95$ \\
Mm4 & $276-370 / 258-349$ & $280 / 308$ & $22 / 32$ & $0.74 / 0.91$ & $0.93 / 0.94$ \\
Mm5 & $189-253 / 175-251$ & $302 / 307$ & $17 / 36$ & $0.78 / 0.95$ & $0.88 / 0.95$ \\
FE17 & $129-193 / 131-225$ & $294 / 302$ & $5 / 36$ & $0.41 / 0.78$ & $0.46 / 0.92$ \\
\hline
\end{tabular}

Worker genotypes $(n)$ were used to estimate allele number $(A)$, and the observed $\left(H_{\mathrm{o}}\right)$ and expected $\left(H_{\mathrm{e}}\right)$ heterozygosity for each population $(\mathrm{CHI} / \mathrm{SIE})$

Mm loci: Kronauer and Gadau (2002), FE17: Gyllenstrand et al. (2002) v2.0.6.4 (Jones and Wang 2010). This program uses a likelihood-based method to simultaneously reconstruct matrilines and patrilines and to assign them to offspring, while accounting for genotyping errors (Wang 2004). Rare matrilines, represented by a single worker genotype, were excluded to minimize overestimating queen number, since some Myrmecocystus species are known to exhibit intraspecific brood raiding (Hölldobler 1976). We also estimated the pedigree effective mate number $\left(m_{\mathrm{e}, \mathrm{p}}\right)$ of each colony with MATESOFT v1.0 (Moilanen et al. 2004). In these analyses, MATESOFT determines whether the worker genotypes are consistent with a single queen having any number of male mates. If so, the program reconstructs the likely queen genotype. Colonies that are not consistent with a single queen are flagged as polygynous and excluded from the $m_{\mathrm{e}, \mathrm{p}}$ analysis. Thus, in addition to the $m_{\mathrm{e}, \mathrm{p}}$ statistics, MATESOFT gives us more conservative estimates of the minimum number of queens necessary to explain all worker genotypes in each colony independent of COLONY.

\section{Relatedness analyses}

We characterized the degree of relatedness within field nests to better understand the source of the sociogenetic patterns revealed by MATESOFT and COLONY. Pairwise intracolonial relatedness between workers $\left(r_{\mathrm{ww}}\right)$ and between nestmate queens $\left(r_{\mathrm{QQ}}\right)$ were estimated using Queller and Goodnight's method (1989) as modified by Lynch and Ritland (1999) using the R package related (Pew et al. 2015; R Core Team 2013). To explore whether the observed relatedness coefficients were consistent with primary polygyny, we used custom R scripts (Supplemental Materials) to first simulate multi-locus genotypes of workers and reproducing queens sampled from the same colony using the COLONY-inferred matriline numbers as well as the population allele frequencies estimated from field data. We then estimated pairwise relatedness coefficients from the simulated genotypes and compared the empirical distribution of the average pairwise relatedness of each simulated sample with the average pairwise relatedness of the actual samples. Pairwise relatedness of simulated workers in each colony was estimated for three scenarios: (1) where the nestmate queens were all unrelated, (2) where some nestmate queens were siblings descended from two to eight unrelated mothers (range based on COLONY estimates, Table 3), or (3) where all nestmate queens were siblings (i.e., shared the same mother). Pairwise relatedness of simulated nestmate queens was also estimated for these scenarios under three additional conditions: where nestmate queens' mothers were either completed unrelated, shared two to three mothers, or descended from the same mother (i.e., all nestmate queens were cousins). Each scenario was simulated 1,000 times and used to estimate the 
Table 3 Sociogenetic results estimated from worker genotypes $(n)$ of field colonies

\begin{tabular}{|c|c|c|c|c|c|c|c|}
\hline Colony & $n$ & $\begin{array}{l}\text { Gyny } \\
\text { (MATESOFT) }\end{array}$ & $\begin{array}{l}\text { Number of mates } \\
\text { (MATESOFT) }\end{array}$ & $\begin{array}{l}\text { Matriline num- } \\
\text { ber (COLONY) }\end{array}$ & $\begin{array}{l}\text { Patriline number/ } \\
\text { matriline (COL- } \\
\text { ONY) }\end{array}$ & $r_{\mathrm{ww}}$ & $r_{\mathrm{QQ}}$ \\
\hline $\mathrm{CHI} 2$ & 30 & Mono & 7 & 1 & 3 & 0.441 & - \\
\hline CHI3 & 27 & Mono & 2 & 1 & 4 & 0.750 & - \\
\hline CHI4 & 26 & Mono & 2 & 1 & 2 & 0.589 & - \\
\hline CHI6 & 30 & Poly & na & 1 & 3 & 0.511 & - \\
\hline CHI8 & 29 & Poly & na & 1 & 3 & 0.327 & - \\
\hline CHI9 & 28 & Poly & na & 2 & 2.5 & 0.575 & 0.196 \\
\hline CHI10 & 29 & Mono & 4 & 2 & 1.5 & 0.580 & 0.06 \\
\hline CHI11 & 28 & Mono & 3 & 1 & 4 & 0.766 & - \\
\hline CHI12 & 28 & Mono & 8 & 1 & 4 & 0.425 & - \\
\hline CHI17 & 28 & Mono & 4 & 1 & 4 & 0.533 & - \\
\hline CHI20 & 25 & Mono & 3 & 1 & 2 & 0.750 & - \\
\hline SIE6 & 24 & Poly & 5 & 5 & 2.4 & 0.169 & 0.114 \\
\hline SIE7 & 25 & Mono & 5 & 2 & 1.3 & 0.518 & -0.127 \\
\hline SIE8 & 30 & Poly & na & 7 & 2.4 & 0.134 & 0.130 \\
\hline SIE9 & 30 & Poly & na & 8 & 2.6 & 0.101 & 0.078 \\
\hline SIE10 & 30 & Poly & na & 8 & 2.1 & 0.035 & 0.019 \\
\hline SIE12 & 29 & Poly & na & 6 & 1.7 & 0.046 & 0.037 \\
\hline SIE14 & 30 & Poly & na & 7 & 2.3 & 0.053 & 0.016 \\
\hline SIE16 & 29 & Poly & na & 2 & 2.0 & 0.510 & 0.329 \\
\hline SIE17 & 25 & Poly & 7 & 2 & 1.5 & 0.285 & -0.104 \\
\hline SIE18 & 26 & Poly & na & 6 & 1.3 & 0.091 & 0.065 \\
\hline SIE20 & 30 & Poly & na & 8 & 2.5 & 0.039 & 0.026 \\
\hline
\end{tabular}

The numbers of male mates inferred by MATESOFT were based on the most likely queen genotypes; for SIE colonies flagged as polygynous, MATESOFT used a subset of workers explainable by a single queen. Matriline and patriline numbers and relatedness coefficients of nestmate queens $\left(r_{\mathrm{QQ}}\right)$ were estimated from COLONY inferences, excluding rare matrilines. Relatedness coefficients estimated from genotypes of actual worker and COLONY-inferred queens are reported in the last two columns, respectively probability of the observed average pairwise relatedness under that particular scenario.

\section{Colony founding in the laboratory}

\section{Sampling}

We set out to compare the colony founding behavior of queens between our two study populations, by sampling newly mated foundresses from the CHI population in 2014 $(n=145)$ and from the SIE population in 2013 and 2015 ( $n=138$ and 125, respectively). Foundresses were captured while searching for nest sites, excavating, or from inside sealed incipient nests, and were classified as haplometrotic if they were alone or pleometrotic if associated with at least one other queen.

In 2013, SIE foundresses were placed into 8-ounce glass jars lined with a 5-cm layer of plaster of Paris and filled with autoclaved moistened soil. Natural co-foundresses were kept together, and haplometrotic and roaming foundresses were added to some natural associations to increase group size or to induce pleometrosis. In 2014 and 2015, each foundress was first put into a glass tube with a moistened cotton ball. Within $24 \mathrm{~h}$ after collection, foundresses were weighed to the nearest $0.1 \mathrm{mg}$ using a microbalance, and then randomly assigned to either haplometrotic or pleometrotic treatment groups. All founding queens were uniquely marked on the dorsal pronotum and mesonotum with nontoxic paint and placed inside cylindrical plastic containers (diameter: $8.41 \mathrm{~cm} \times$ depth: $3.33 \mathrm{~cm}$ ) lined with Plaster of Paris or Hydrostone and filled with autoclaved moistened soil. Artificial pleometrotic colonies were formed using queens collected in the same year and population, with the number of foundresses assigned to each colony ranging from two to four depending on the year and availability of founding queens (Table 1).

\section{Foundress survival}

To investigate population variation in founding strategy and its effects on foundress survival, we monitored queen mortality for at least 60 days following colony founding $\mathrm{We}$ 
modelled the effects of the initial foundress group size on the survival probability with a Kaplan-Meier survival curve using the survival package in R (Therneau and Grambsch 2000; Therneau 2015); foundress live weight was included as a covariate in the 2014 and 2015 models. The proportional hazard assumption was verified for each analysis. Power analyses were performed with the powerSurvEpi package in R (Qiu et al. 2012).

\section{Worker production}

Myrmecocystus mendax queens are fully claustral (Snelling 1976), rearing the minims using their metabolic reserves. Following minim emergence, incipient colonies were moved to observation nests, i.e., plastic containers (length: $10.95 \mathrm{~cm} \times$ width: $10.95 \mathrm{~cm} \times$ depth: $3.50 \mathrm{~cm}$ ) lined with plaster of Paris or Hydrostone. Colonies were watered and fed once a week on a diet consisting of $4 \mathrm{ml}$ of water, $4 \mathrm{ml}$ of honey-sucrose solution, and ad libitum mealworms.

The effects of foundress number on the number of workers produced by each colony and per queen were examined using linear mixed-effect models implemented in the R package lme 4 (Bates et al. 2018). In both analyses, colony age was included as a covariate and nest as a random effect; the live weight of foundresses was included as second covariate in the per-queen analysis. For each colony, the total number of workers was counted weekly from photographs for about three months following foundation, and the number of workers produced per-queen was estimated by dividing the total worker number by the number of foundresses.

\section{Replete production}

Repletes or honeypots, from which the genus Myrmecocystus derives its colloquial name, are workers specialized on storing liquid nutrients in their crop as long-term reserves. We investigated the effects of founding strategy on laboratory colonies' replete production potential by counting the number of workers with visibly filled crops ("filled" workers). In mature colonies, repletes can be quickly identified by a greatly distended gaster inflated by a heavy crop load (Fig. 1c). However, it is more challenging to identify developing repletes in incipient colonies based on morphology alone, because they can be indistinguishable from nonreplete workers with a full crop such as returned foragers. Anecdotal observations indicated that most filled workers in incipient laboratory colonies were either repletes in development or foragers transporting liquid to supply the repletes. Therefore, including the latter in this analysis is appropriate.

In the 2015 SIE laboratory population, filled workers started to appear early in colony development, around two weeks after minims had begun to emerge. Filled workers can be distinguished from unfilled individuals by the visible stretching of the intersegmental membrane connecting the first and second gastral tergites (Fig. 1d). We tested to see whether we could reliably distinguish these two worker types visually using the ratio of the gastral width to head width (GH). Filled workers are expected to have a greater ratio due to the gaster being inflated. We sampled 48-day-old laboratory colonies from the 2015 SIE cohort with 10 or more workers with stretched membrane $(n=13)$. For each colony, the $\mathrm{GH}$ ratio was obtained from photographs for six workers chosen randomly, including three with stretched intersegmental membrane and three without any visible stretching $(n=78)$, using the program Fiji (Schindelin et al. 2012). We found that the GH ratio of workers with stretched membrane was significantly greater than those without (stretched: $1.50 \pm 0.02$, no stretching: $1.22 \pm 0.02$; linear mixed-effect model, $\beta=-0.28, t=-12.7, P<0.001)$. This statistical difference validates our qualitative method to distinguish filled and unfilled workers. We then counted filled workers in the remaining 2015 SIE colonies on days 48 and 83 (Table 1), and analyzed the log-transform data using a linear regression model with colony age and total worker number included as covariates.

\section{Intercolonial competition}

To examine the effect of worker number on the outcome of competition between incipient colonies, we conducted two independent brood-raiding experiments, one for the 2014 CHI colonies (age: $150-160$ days) and one for the 2015 SIE colonies (age: 92 days). We induced raiding by connecting two test colonies to a shared arena (length: $10.95 \mathrm{~cm} \times$ width: $10.95 \mathrm{~cm} \times$ depth: $3.50 \mathrm{~cm}$ ). The distance between nest entrances was fixed at $11 \mathrm{~cm}$, which is within the range seen between incipient colonies in the field (Eriksson, per. obs.). In each pair, the colony with more workers was designated as the larger colony, and its rival as the smaller colony. In pairs where queen number differed between rivals, larger colonies usually also had more queens and pupae. Pairing combinations based on queen number are listed in Table 1 ("Intercolonial competition" section). We scanned all pairs once every hour for the first seven hours and subsequently every $24 \mathrm{~h}$ for up to 30 days. For each pair, observation stopped when either at least one queen had died or after 30 days. Initially only water was provided to each pair, and honey-sucrose solution was subsequently added 7 days after the experiment started.

The majority of pairs from the CHI experiment were monogynous colonies ( $n=11$ pairs, combination: 1 queenvs-1 queen, 1 queen-vs-2 queens; Table 1) because most laboratory colonies started with multiple foundresses from this population did not survive (Fig. 2c) due to queen-queen aggression and queen culling. Experimental CHI colonies had on average $34.5 \pm 6.15$ workers, with 


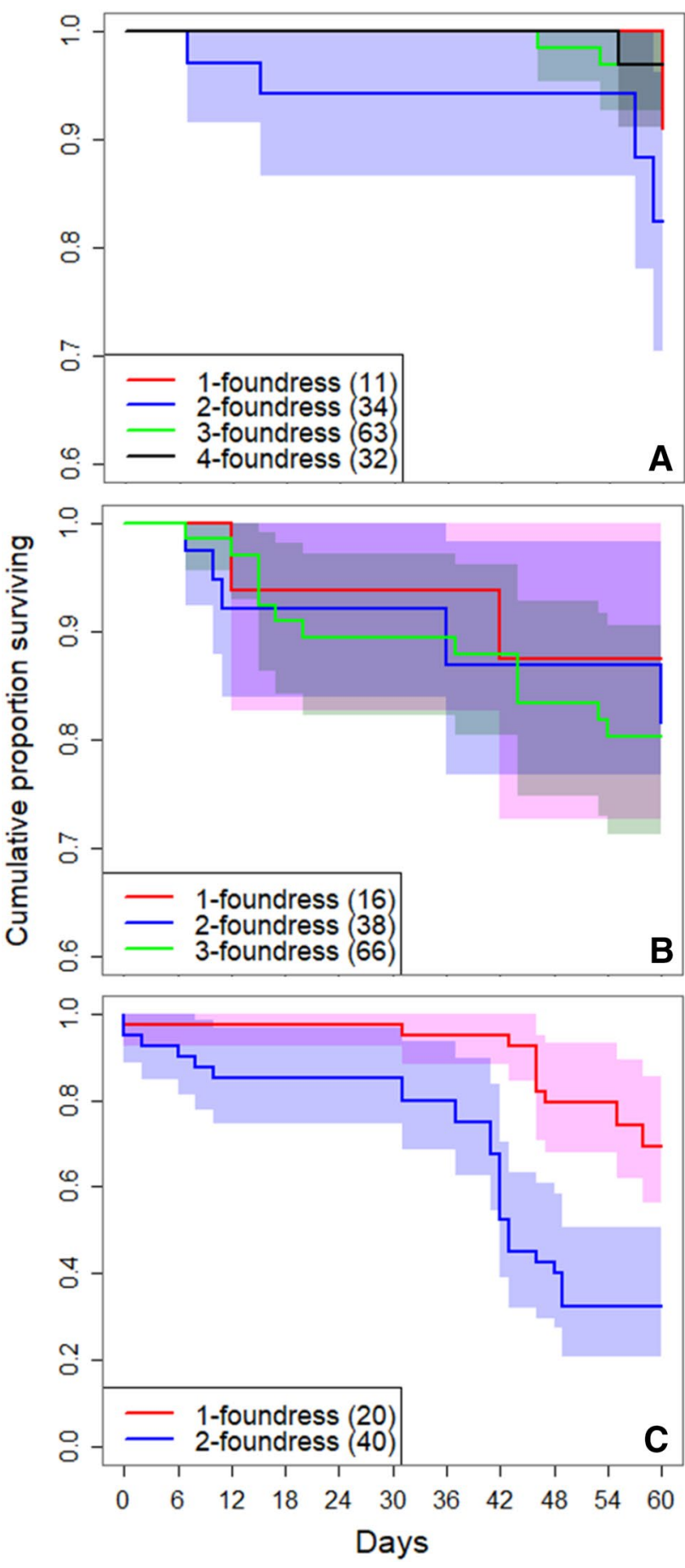

Fig. 2 Kaplan-Meier foundress survival curves of the first 60 days after colony founding. Foundress number did not have any significant effect in SIE laboratory colonies (2013: a, 2015: b) but did in CHI colonies (2014: c). 95\% confidence bands are shaded. Note that the $y$-axis of $\mathbf{a}$ and $\mathbf{b}$ was scaled to improved clarity. Numbers of queens are in parentheses

larger colonies having $2.9 \pm 0.26$ times (range 1.9-4.3) more workers than smaller rivals. In the 2015 SIE experiment, pairs were made up of 92-day-old colonies having on average of $35.54 \pm 2.42$ workers. Larger colonies had
$1.59 \pm 0.09$ times (range 1.05-2.84) more workers than smaller rivals. On the other hand, more queen number combinations were tested in the SIE experiment, due to the difference in queen tolerance in this population $(n=26$ pairs, combination: 1 queen-vs- 1 queen, 1 -vs-2, 1 -vs-3, 2-vs-2, and 2-vs-3; Table 1).

To investigate how worker number influences queen survival during staged brood raids, we used a linear regression model to examine the association between the worker number ratio between the larger and smaller paired colonies with a queen survival index. The queen survival index was calculated for each colony pair by taking the difference between the proportion of surviving queens in the larger colony (i.e., the number of queens surviving divided by the number present before raid) and the proportion surviving in the smaller colony. The index equals zero if all queens survive, and is either positive or negative depending on whether queen survival is greater in the larger or smaller colony, respective. For example, suppose that a colony starting the experiment with three queens is paired with a single-queen colony. If no queen dies, the index will be equal to $3 / 3-1 / 1=0$. In contrast, the index will be equal to $3 / 3-0 / 1=1$ if the queen from the smaller colony dies, or $2 / 3-1 / 1=-0.33$ if a queen from the larger colony dies.

In 2015, some paired SIE colonies fused, i.e., all surviving queens, workers, and brood of both colonies moved into the same nest. To determine whether the relocated queens continue to reproduce after fusion, we genotyped secondand-third-instar larvae and all surviving queens in two fused colonies about 200 days following the fusion event, and determined the maternity of each larva using the program COLONY (Table 5). The developmental stage of the larvae and the latency between fusion and sampling ensured that the genotyped larvae were produced after fusion. Original queens were defined as queens that remained in their original nest, and relocated queens were queens that moved from their original nest.

\section{Notes on statistics}

Normality and homoscedasticity assumptions were tested in $\mathrm{R}$ for all datasets using the Shapiro-Wilk test and the Levene test, respectively. Residual linearity, normality, and homoscedasticity assumptions were tested for all models by examining diagnostic plots. Data violating the normality assumption that could not be transformed were analyzed with non-parametric statistics. Non-parametric post hoc tests for multiple samples were implemented using the $\mathrm{R}$ package PMCMR (Pohlert 2014). All averages are reported with $( \pm)$ standard errors. Technical caveats of COLONY and MATESOFT, simulation files, and raw data are provided in the Supplemental Materials. 


\section{Results}

\section{Field colonies}

\section{Colony founding strategy}

The distribution of founding strategies differed between the SIE and CHI populations. Whereas all 125 founding queens that were collected in 2014 in the CHI population were haplometrotic, collections of founding queens in 2013 and 2015 in the SIE population indicated the presence of both haplo- and pleometrosis $\left(n_{2013}=10\right.$ haplometrotic, 9 pleometrotic; $n_{2015}=53$ haplometrotic, 3 pleometrotic). Specifically, we observed the following distribution in 2013: six founding events with two foundresses, one with three foundresses, and two with four foundresses. In 2015, all three pleometrotic events involved two foundresses.

\section{Queen number}

Colonies from the two focal populations differed in the frequency and magnitude of polygyny as inferred from COLONY analyses of worker samples. The majority of mature colonies from the SIE population were polygynous $(91 \%, n=11)$, whereas the majority of the CHI colonies were monogynous $(72 \%, n=11)$; see "Gyny" section in Table 3. This difference was significant (Fisher's exact test, $P<0.01)$. SIE colonies also had on average more matrilines per colony (Table 3, SIE: $6.27 \pm 0.83$ matrilines, CHI: $1.18 \pm 0.12$ matrilines; two-tailed asymptotic Wilcoxon-Mann-Whitney test, $Z=-4.0, P<0.001$ ). Additionally, the same number of matrilines, seven, was estimated for colony SIE 14 using either 21 winged females or 30 workers (Table 3 ). Hence, at least for this colony multiple queens contributed not only to the worker force but also to the next generation of winged sexuals.

\section{Mating frequency}

MATESOFT and COLONY provided evidence of polyandry in both populations (Table 3). MATESOFT estimated a $m_{\mathrm{e}, \mathrm{p}}$ of 1.44 with a $95 \%$ confidence interval of $1.22-1.73$ for the monogynous $\mathrm{CHI}$ colonies $(n=8)$. To obtain an estimate for the highly polygynous SIE population, we analyzed COLONY-inferred matrilines where we had genotypes for at least ten workers each from three colonies (Table 3). We estimated a $m_{\mathrm{e}, \mathrm{p}}$ of 1.13 for SIE matrilines (95\% CI 1-1.31), which was not significantly lower than the MATESOFT estimate for the CHI value. On the other hand, COLONY estimates suggested that SIE matrilines had significantly fewer mates than $\mathrm{CHI}$ matrilines (SIE: $2 \pm 0.15$ patrilines, CHI: $3 \pm 0.28$, two-tailed Welch two-sample $\mathrm{t}$ test on log-transformed data, $t=-2.96$, $d f=18.78, P=0.008$ ).

\section{Intracolonial relatedness}

Nestmate relatedness composition within field colonies varied between populations and was consistent with the apparent difference in social structure. Specifically, the average $r_{\mathrm{ww}}$ in the predominantly monogynous CHI colonies $(0.57 \pm 0.04, n=11)$ was significantly higher than in the highly polygynous SIE colonies $(0.18 \pm 0.05, n=11$; twotailed asymptotic Wilcoxon-Mann-Whitney test, $Z=49.6$, $P<0.001$, Table 3 ). The average $r_{\mathrm{QQ}}$ of SIE colonies was not significantly different from zero $(0.053 \pm 0.04, n=11$, onesample two-tailed $t$ test, $t_{10}=1.45, P=0.18$ ). To investigate whether the SIE data were consistent with primary polygyny, we compared the average pairwise relatedness of nestmates sampled from these colonies with the average pairwise relatedness of nestmates simulated under three scenarios that assumed that nestmate queens were either (1) all unrelated, (2) a mixture of related and unrelated individuals, or (3) all related. Overall, the simulation results suggested that nine of the 11 SIE colonies examined were consistent with nestmate queens either were all unrelated or composed of both

Table 4 Results of the comparisons between pairwise relatedness estimated from simulated workers and (/) nestmate queens, and relatedness estimated from worker samples and COLONY-inferred queens of SIE field colonies

\begin{tabular}{llll}
\hline Colony & \multicolumn{2}{l}{ Scenario } & \\
\cline { 2 - 4 } & All unrelated & Mix relatedness & All related \\
\hline SIE6 & $+/+$ & $+/+$ & $-/-$ \\
SIE7 & $+/+$ & $+/-$ & $+/-$ \\
SIE8 & $+/+$ & $+/+$ & $-/-$ \\
SIE9 & $+/+$ & $-/+$ & $-/-$ \\
SIE10 & $-/+$ & $-/-$ & $-/-$ \\
SIE12 & $-/+$ & $-/+$ & $-/-$ \\
SIE14 & $+/+$ & $-/-$ & $-/-$ \\
SIE16 & $+/+$ & $+/-$ & $+/+$ \\
SIE17 & $-/+$ & $-/-$ & $-/-$ \\
SIE18 & $+/+$ & $-/+$ & $-/-$ \\
SIE20 & $+/+$ & $-/+$ & $-/-$ \\
\hline
\end{tabular}

Worker genotypes were simulated for scenarios where nestmate queens were all unrelated, were descended from two to eight unrelated mothers (mix relatedness), and were all related. Nestmate queen genotypes were simulated for scenarios in which they were all unrelated, were a mixture of related and unrelated individuals, and were all related (siblings or cousins). Scenarios that cannot be rejected at a level of $P<0.05$ are marked with plus signs (+) 
related and unrelated individuals (Table 4, see Supplemental Materials for $P$ values for each colony under each scenario examined).

\section{Laboratory colonies}

\section{Foundress survival}

The pattern of queen mortality in laboratory colonies was consistent with the differences in founding behavior observed in the two field sites. CHI foundresses collected in 2014 exhibited strong antagonism when forced to associate in the laboratory. Antagonistic displays and outright aggressive behaviors were seen in eight of the nine queen pairs observed (standing on top $=5$ pairs, threat displays with open mandibles $=8$, fighting $=3$ ). In all forced foundress associations, at least one of the queens died during the colony founding process. In contrast, 2015 SIE queens were generally tolerant when placed in groups. SIE queens were significantly heavier than CHI queens $(74.4 \pm 0.62 \mathrm{mg}$, CHI: $63.6 \pm 0.41 \mathrm{mg}$; two-tailed Mann-Whitney $U$ Test, $W=1553.5, P<0.001)$.

The survivorship of SIE foundresses in the first 60 days following colony initiation did not depend on the initial foundress number in 2013 and 2015 (Fig. 2a, b; Cox hazard ratio $=0.52$ and $1.04 ; 95 \%$ CI $0.27-1.02$ and $0.55-1.93$, $P=0.057$ and 0.9 ; Wald test, $P=0.057$ and 0.90 , respectively). Live weight had a small but significant effect on survival in 2015 (Cox hazard ratio $=1.044 \times 10^{-52}, 95 \% \mathrm{CI}$ $5.029 \times 10^{-81}$ to $2.17 \times 10^{-24}, P<001$; Wald test, $P=0.001$; no data for 2013). The proportional hazard assumption was satisfied in both years (Schoenfeld residuals test, $P$ values $>0.05$ ), and the power of each analysis was at least $90 \%$.
On the other hand, $\mathrm{CHI}$ foundress survivorship was negatively affected by foundress number (Cox hazard ratio $=3.5$, 95\% CI 1.77-6.97, $P<0.001$; Wald test, $P=0.002$, Fig. 2c). In this case, the proportional hazard assumption was rejected (Schoenfeld residuals test, $\rho=-0.33, \chi^{2}=3.91, P=0.048$ ), suggesting that the initial number of foundresses had a disproportional effect on queen survival over time. Indeed, survivorship of $\mathrm{CHI}$ foundresses in forced associations declined more sharply after around day 40 relative to foundresses kept by themselves (Fig. 2c). This decline coincided with the emergence of the first workers (i.e., minims), which were observed actively participating in queen culling (Eriksson, per. obs.). Live weight had no effect on survivorship (Cox hazard ratio $=-14.8 ; 95 \% \mathrm{CI} 1.11 \times 10^{-34}$ to $1.17 \times 10^{21}$, $P=0.65$ ). The power of this analysis was at least $90 \%$.

\section{Worker production}

Minims emerged significantly earlier in the 2015 SIE colonies than in the 2014 CHI colonies (SIE: $33.05 \pm 0.19$ days, CHI: $36.38 \pm 0.29$ days; two-tailed asymptotic Wilcoxon-Mann-Whitney test, $Z=7.59, P<0.001$ ), but founding strategy had no effect on minim emergence rate in either population.

Foundress number and colony age had variable influences on the total number of workers produced in each nest each year. In 2013, worker number was not associated with colony age or an age-by-foundress number interaction. However, foundress number did have a significant positive effect on worker production (Fig. 3a, $\beta=8.33, t=3.07, P=0.004$ ). The interaction term was again not significant in 2015 , but both foundress number (Fig. $3 \mathrm{~b}, \beta=8.08, t=4.65, P<0.001$ ) and colony age $(\beta=0.157, t=8.28, P<0.001)$ were
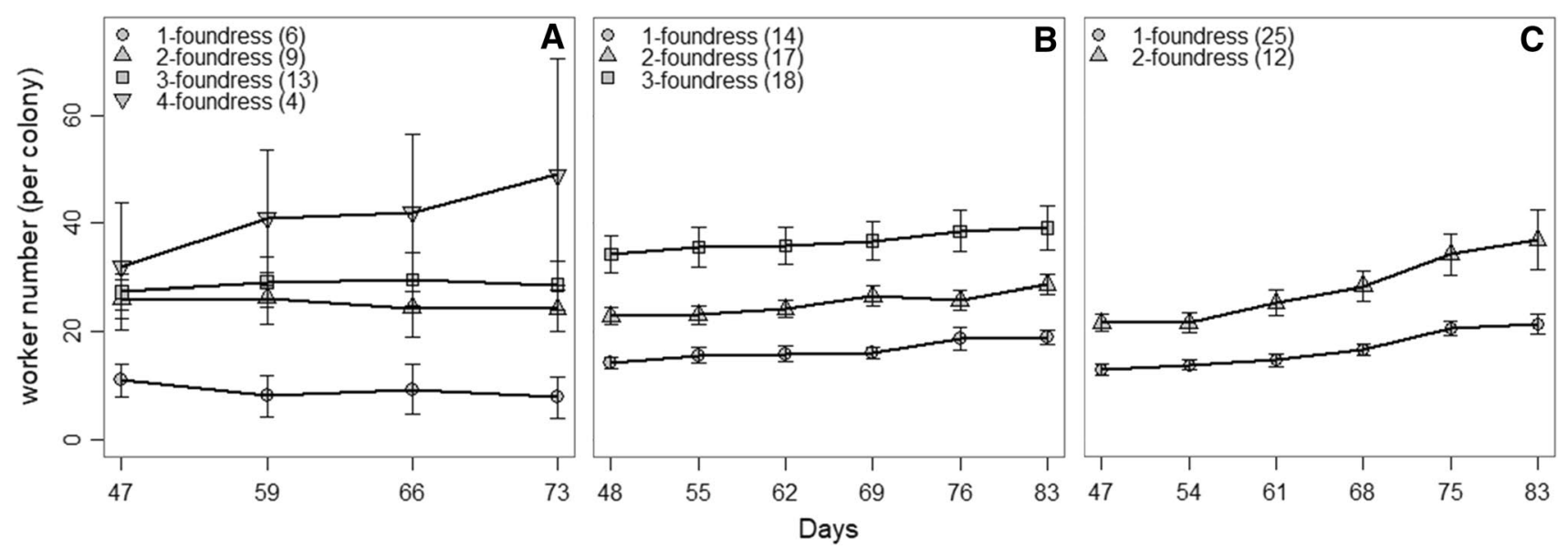

Fig. 3 Total number of workers produced during early development of incipient laboratory colonies with different number of foundresses. There were significant main effects of foundress number and colony age (i.e., days after founding) on worker number in SIE colonies (a, b), while there was a significant interaction between foundress number and colony age in $2014 \mathrm{CHI}$ colonies (c). Each shape represents the average at the corresponding time point with standard error bars. Numbers of colonies are in parentheses 
positively associated with worker number. In contrast, there was a significant interaction in $2014(t=3.83, P<0.001)$, and no overall effect of colony age and foundress number. However, a post hoc test revealed that 2-foundress colonies had significantly more workers than 1-foundress colonies starting on day 61 onward (Fig. 3c, $P$ values $<0.05$ ).

In term of the number of workers produced per queen, colony age had a significant positive effect in both the 2014 CHI (Fig. 4a, $\beta=0.241, t=12.99, P<0.001$ ) and the 2015 SIE colonies (Fig. $4 \mathrm{~b}, \mathrm{t}=2.31, P=0.021$ ). We also detected a significant negative interaction between the number and live weight of SIE foundresses (Fig. $4 \mathrm{~b}, \beta=-0.44, t=$ $-2.86, P=0.004)$ in 2015. In contrast, no significant effects on worker production per queen were detected in the 2013 SIE colonies.

\section{Replete production}

The number of filled workers in 2015 SIE laboratory colonies was affected by founding strategy (adjusted $R^{2}=0.208$, $\left.F_{3,87}=8.86, P<0.001, \beta=0.56, P=0.011\right)$ and worker number $(\beta=0.016, P=0.022)$, but not by their interaction or colony age. Specifically, the average proportion of filled workers was greater in pleometrotic colonies relative to haplometrotic colonies after 48 (haplometrotic: $14.65 \pm 5.80 \%$, pleometrotic: $23.83 \pm 3.28 \%$ ) and 83 days following colony initiation (haplometrotic: $8.36 \pm 2.78 \%$, pleometrotic: $13.64 \pm 1.96 \%)$.

\section{Intercolonial competition}

Queen mortality occurred in all CHI pairs $2.45 \pm 0.46$ days after nests was connected. At the end of the experiment, only 13 of 24 queens survived (54.2\%), 10 of which were from the larger colonies (76.9\%). However, the relationship between workforce size and queen survivorship was not significant, possibly due to the small sample size. Surviving brood and workers from smaller colonies were eventually relocated to the nest of the larger colonies in $82 \%$ and $91 \%$ of the pairs $(n=11)$, respectively.

In contrast, queen mortality occurred in only 10 of the 26 SIE pairs $(38.5 \%), 11.1 \pm 1.81$ days after nests were connected. Furthermore, 84 of 96 queens (88\%) survived the experiment, 54 (64\%) of which belonged to the larger colonies. Mortality occurred earlier for queens from smaller colonies ( $9.33 \pm 1.61$ days, $n=6$ queens) than for queens of larger colonies (13.2 \pm 3.47 days, $n=5$ queens) but this difference was not significant (two-tailed Mann-Whitney $U$ test, $W=9, P=0.16)$. In 26 pairs $(70 \%)$, the larger colony suffered fewer queen deaths. Linear regression showed that the natural $\log$ of the worker number ratio was positively correlated with the natural $\log$ of the queen survival index +1 (Fig. 5; adjusted $R^{2}=0.18, F_{1,24}=6.36, \beta=0.634$, $P=0.019)$. In other words, the survival probability of queens from larger colonies increased as the difference in workforce size increased between the contestants.

Surviving brood and workers of rival colonies were eventually found together in the larger colony's nest in 58\% and $62 \%$ of the pairs, respectively. Unexpectedly, 29 queens relocated with their brood and workers to the rival's nest and survived until the end of the experiment. These fusion events prevented unambiguous determination of the winning colony in 20 pairs, and occurred in all pairing combinations (1queen-vs-1queen: 20\%, 1-vs-2: 25\%, 2-vs-2: 10\%, 1-vs-3: $25 \%$, 2-vs-3: 20\%, $n=20$ ). Relocated queens often originated from smaller colonies (12 cases or $60 \%$ ). After the experiment, marked relocated queens were seen without detectable injuries, being groomed and fed by workers, and reproduced in their new home.

All queens and young larvae from two fused colonies were genotyped on day 279 and 304 after fusion, respectively, to determine the reproductive status of the queens.
Fig. 4 The number of workers produced on a per-queen basis during early development of incipient laboratory colonies started by different number of foundresses. Only colony age had a significant positive effect in 2014 CHI colonies (a), and there was an interaction between foundress number and foundress live weight in 2015 SIE colonies (b). Each shape represents the average at the corresponding time point with standard error bars. Numbers of colonies are in parentheses

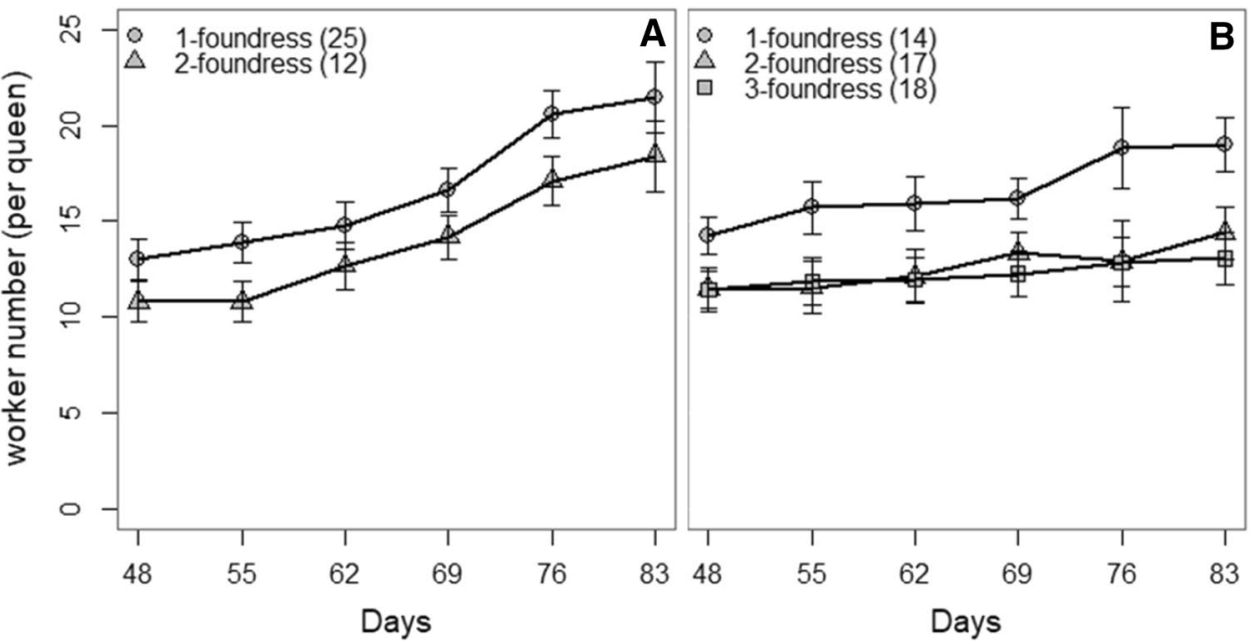




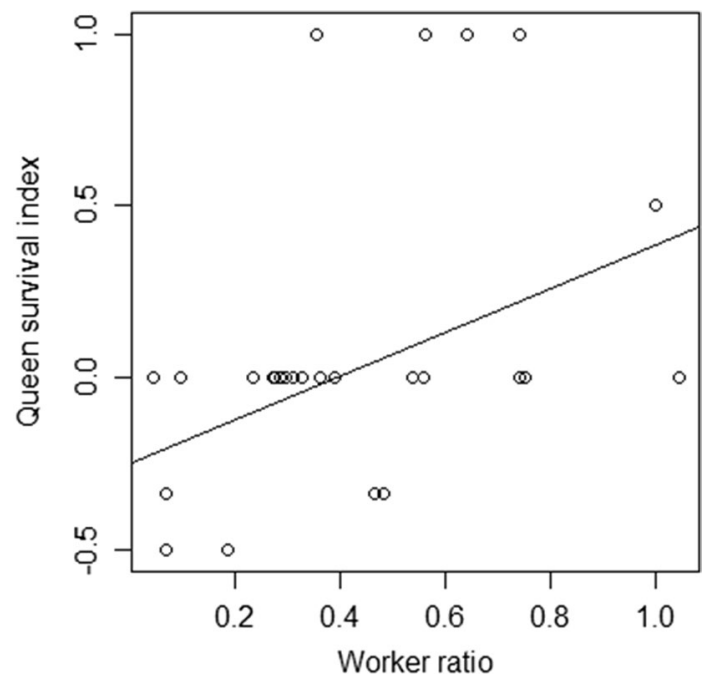

Fig. 5 The relationship between the natural log-transformed worker ratio and the natural log-transformed queen survival index +1 estimated from paired SIE 2015 laboratory colonies. Each open circle represents a colony pair. The queen survival index equals zero if all queens survive, and is either positive or negative depending on whether queen survival is greater in the larger or smaller colony, respective. A linear regression model $\left(F_{1,24}=6.36, P=0.019\right)$ suggested that the likelihood of queen survival correlates with the asymmetry in workforce size between interacting colonies

All larvae could be assigned unambiguously to one of the queens in the colony. Overall, the genotype profiles of the larvae showed that both original and relocated queens reproduced in fused colonies, with $4 \%$ of the larval genotypes assigned to the relocated queens in the three-queen colony and $30 \%$ in the four-queen colony (Table 5).

\section{Discussion}

The sociogenetic analyses and laboratory experiments described here demonstrate that $M$. mendax populations in the Chiricahua (CHI) and Sierra Ancha Mountains (SIE) differ greatly in their social organization as mature colonies, in their colony founding strategy, and in the behaviors exhibited during interactions between queens and between colonies. There are multiple lines of evidence for primary polygyny in the SIE population. We observed pleometrosis in the field. The genetic data indicated that mature field colonies contained a number of unrelated queens (Table 4), and that there are multiple matrilines in winged females of colony SIE14. Furthermore, SIE foundresses collected in multiple years successfully established primary polygyny in laboratory colonies (Fig. 2a, b). In contrast, the CHI population predominantly exhibited haplometrosis and monogyny. This is supported by our findings that the genetic profiles of most mature field colonies are consistent with monogyny.
Table 5 The number of larvae and queens genotyped for two fused colonies, and the queens' identity (original or relocated) and their respective contribution to the larva sample

\begin{tabular}{lllllll}
\hline Colony & Larva & \multicolumn{2}{l}{ Surviving queen } & & \multicolumn{2}{l}{ Contribution $(\%)$} \\
& & Original & Relocated & & Original & Relocated \\
\hline $\begin{array}{l}\text { SIE_L25- } \\
43\end{array}$ & 46 & 2 & 2 & 69.57 & 30.43 \\
$\begin{array}{l}\text { SIE_L24- } \\
49\end{array}$ & 28 & 2 & 1 & & 96.43 & 3.57 \\
\hline
\end{tabular}

In addition, after a nuptial flight in 2014 all of the incipient colonies that we found contained only one queen. When CHI foundresses were placed together in artificial pleometrotic groups, the queens behaved aggressively toward nestmate queens, which often resulted in early queen mortality (Fig. 2c). Lastly, queen culling was observed in laboratory colonies, leading to secondary monogyny (Fig. 2c).

The large variation in the frequency of pleometrosis between 2013 and 2015 at the SIE field site is puzzling, and we have no satisfactory explanation for this observation. The 2015 mating flight started much later in the day (6 PM versus 3PM in 2013) which may have left foundresses with little time to mate and form groups before nightfall. It is also possible that this delay biased the sampling of foundress associations, which may continue to be formed after dark. Alternatively, perhaps the frequency of pleometrosis depends on foundress density and the number of foundresses released by local colonies was lower in 2015. This observation raises the possibility that the CHI population may experience similar fluctuations, and that additional fieldwork may reveal that pleometrosis and primary polygyny sometimes occur in this population. Indeed there was some evidence in laboratory colonies of CHI foundresses cooperating even after minims had emerged. In addition, $18 \%$ of mature field CHI colonies genotyped had a signature of multiple matrilines, and multiple closely related queens can produce workers with relatedness coefficient similar to a single polyandrous queen (Table 2 in Keller 1995). Despite these caveats, multiple sources of data demonstrate that these two focal populations differ in social behavior and colony structure.

Polyandry was detected in both $M$. mendax populations (Table 3). In contrast, two other better-studied congeners, M. mimicus and M. depilis, are characterized by monoandry (Kronauer et al. 2003). The power to detect patrilines associated with SIE matrilines was lower than that of their CHI counterparts due to the presence of multiple matrilines in SIE colonies, and hence fewer workers per matriline were available for analysis. Multiple mating by queens increases intracolonial genetic diversity and has been suggested as an adaptation in advanced eusocial insects (Palmer and Oldroyd 2000). In particular, mating frequency has been shown to be 
positively correlated with pathogen resistance (Hughes and Boomsma 2004), task specialization (Oldroyd and Fewell 2007), and colony productivity and fitness (Mattila and Seeley 2007). Our results from the COLONY analyses are also consistent with the genetic variability hypothesis, which predicts that polyandry should be more common in monogynous populations than in polygynous populations if there are costs associated with multiple mating and if polygyny already increases intracolonial genetic diversity (Keller and Reeve 1994). This pattern has been observed in some studies (Keller and Reeve 1994; Hughes et al. 2008) but is absent in others (Pedersen and Boomsma 1999; Schmid-Hempel and Crozier 1999; Overson et al. 2011).

Intraspecific variation in social structure has been observed in only one other congener so far, M. mimicus, which exhibits primary and secondary monogyny as well as some evidence of primary polygyny (Wheeler 1917; Bartz and Hölldobler 1982; Hölldobler et al. 2011). M. mimicus and M. mendax are not sister species (Snelling 1976; Kronauer et al. 2004). M. mimicus inhabits drier habitats at lower elevations than M. mendax (Snelling 1976) but the two species share similar life history features including repletism, ritualized territorial combat (i.e., tournament), and brood raiding. On the other hand, very little is known about the social structure of the remaining Myrmecocystus taxa. M. depilis, the sister species of M. mimicus, is likely obligatorily monogynous (Hölldobler et al. 2011). Similarly, M. mexicanus, a member of the nocturnal subgenus, was consistently found to have a single queen in excavated colonies (Conway 1980; Conway 1983; Conway 1990). These observations suggest that primary polygyny is probably a rare derived trait in this genus.

We hypothesize that primary polygyny in the M. mendax population at the SIE site is adaptive. Laboratory experiments consistently showed a positive relationship between the numbers of foundresses and workers produced in incipient colonies across multiple years and populations (Fig. 3). Having a large workforce confers several important benefits for $M$. mendax colonies during the founding and early ergonomic growth phase. We showed that young laboratory colonies with multiple foundresses generally had greater replete production potential than haplometrotic colonies. This finding can be explained by multi-queen colonies having more workers that can either serve as repletes or forage to supply repletes, and suggests the possibility that replete production is prioritized in early development. Additionally, tournament and raiding have been observed in M. mendax at the SIE field population (Eriksson, per. obs.) and our intercolonial competition experiments showed that larger colonies have an advantage in term of queen survival (Fig. 5).

Primary polygyny has downstream costs to individual queens in term of sharing reproduction (Gadau and Fewell 2009, Haney and Fewell 2018). Per-capita production of sexual offspring is likely constrained by resource partitioning among nestmate queens. In addition, if there are "cheating" queens that bias their offspring production in favor of sexuals, the other queens need to increase their contribution to maintaining the colony's worker population size by reducing their own production of sexuals. These costs to reproductive fitness are highest when cooperating queens are not related and consequently share no inclusive fitness, but are ameliorated in secondarily polygynous colonies, which adopt daughter queens (Fournier and Keller 2001; Heinze et al. 2001; Fournier et al. 2004). This raises the question of why polygyny is still maintained in some pleometrotic $M$. mendax colonies. We propose that the evolution of primary polygyny in this species may be driven in part by colony density and territorial competition selecting for colonies with large workforces. We observed that colony density is higher in the SIE population (unpublished data), which likely reduces the availability of nesting sites and increases predation risks for incipient colonies by mature colonies. These pressures may select for pleometrosis. High colony density can also result in greater overlap between territories and reduces resource availability, which may increase the frequency and severity of territorial conflicts. As adjacent colonies grow, those able to maintain a larger workforce are better at outcompeting neighbors. These dynamics could also explain why all of the sampled SIE mature field colonies were polygynous (Table 3 ) even though the majority of colony founding events recorded from the field were haplometrotic (52.6 and 94.6\% in 2013 and 2015, respectively) if haplometrotic colonies are much less likely to survive to reproductive maturity than their pleometrotic counterparts. Alternatively, colony fusion (discussed below) between haplometrotic incipient colonies in the SIE population may regularly lead to polygynous mature colonies. The rarity of polygyny in the CHI population might be explained in part by the observed lower density of mature colonies (unpublished data), which suggests that the pressures of intercolonial competition are less severe here and that the benefit of having a larger workforce is not sufficient to select for pleometrosis and primary polygyny. Hence, primary monogyny may be the most evolutionarily stable strategy for queens at this site.

We speculate that if there is strong selection for a larger workforce in the SIE population, then several alternative mechanisms enabling colonies to increase queen number might be favored (e.g., primary polygyny, fusion of incipient colonies, adoption of related and unrelated queens into mature colonies). Indeed, relatedness estimates of some SIE field colonies are consistent with a mixture of primary and secondary polygyny (Table 4), and colony fusion occurred frequently following brood raids in the laboratory. There is also circumstantial evidence of queen adoption and colony fusion in the SIE field population (Eriksson, per. obs.), 
further suggesting that these phenomena do occur naturally. Fusion has been reported in other polygynous species (Vásquez and Silverman 2008; Guénard et al. 2016) and has been proposed as one of several mechanisms generating polygyny secondarily (Crozier and Pamilo 1996). However, colony fusion has been thought to be restricted to unicolonial species lacking territoriality (Passera 1994). M. mendax workers from the SIE population readily assumed the lateral display posture (Fig. 1a, b), a stereotypical territorial behavior in honey ants (Hölldobler 1976). Furthermore, brood raiding between laboratory colonies caused queen death, and mature field colonies were seen engaging in tournaments as well as raiding and killing queens of incipient colonies (Eriksson, per. obs.). These observations indicate that the SIE population is not unicolonial. It is unclear why colonies would accept unrelated queens, as seen in the laboratory. One possibility is that adding queens can serve as insurance (Landi et al. 2003) or can contribute to future capacity of the colony to produce workers, and that these benefits may compensate for low relatedness among nest members (Gadau et al. 1998). In addition, high colony density may increase the frequency of encounter between neighboring nests and select for fusion due to the higher probability of queen survival in colonies with larger workforces during brood raiding (Fig. 5; Giraud et al. 2002).

Perhaps primary polygyny, queen adoption, and colony fusion all co-occur in the SIE population and together can explain the fact that all mature field colonies analyzed in this work were polygynous, and have higher queen number than observed in natural pleometrotic events (Table 3). There remain many open questions about the social polymorphism detected in $M$. mendax, including the feedback relationship between colony density and queen tolerance, pleometrosis, and colony fusion, how environmental factors influence nestmate recognition, and whether the occurrence of fusion depends on colony size or age. In any case, queen number in M. mendax seems to be a plastic trait that can vary substantially between populations and over the course of colony development. It remains challenging to identify the environmental and intrinsic factors influencing the evolution of queen number in this species, but the diversity of life history features dependent on queen number and the presence of social structure variation makes $M$. mendax a promising study system for both the proximate and ultimate mechanisms of queen tolerance and social polymorphism in ants.

Acknowledgements We thank Stephen Pratt and Jennifer Fewell for intellectual contributions and Christian D'Orgeix, Harry Grissom, Martin Helmkampf, Asia (Joana) Sulich, Rafael Testai, and Lothar Wissler for their assistance with field work. Special thanks to Christina Kwapich for critically reading the manuscript, and Robert (Bob) Johnson for donating his time, specimens, and taxonomic expertise. This research was supported by the National Science Foundation (a Graduate Research Fellowship to THE), the American Museum of Natural
History (a Theodore Roosevelt Memorial Grant to THE), the Sigma Xi Scientific Research Society-National and ASU Chapters (two Grantin-aid of Research to THE), the School of Life Sciences Research and Training Initiative at Arizona State University (a Field Work Assistant Grant to THE), the School of Life Sciences Undergraduate Research Program (research fellowships to THE), Barrett the Honors College at Arizona State University (research funding to THE), the Graduate and Professional Student Association at Arizona State University (a Jumpstart Grant to THE), and the Arizona State University Foundation (a grant to Bert Hölldobler). JG was partly funded by the German Research Foundation (DFG) as part of the SFB TRR $212\left(\mathrm{NC}^{3}\right)$. We are also grateful for the careful reading of this manuscript provided by several anonymous reviewers, whose comments have greatly improved the text.

OpenAccess This article is distributed under the terms of the Creative Commons Attribution 4.0 International License (http://creativeco mmons.org/licenses/by/4.0/), which permits unrestricted use, distribution, and reproduction in any medium, provided you give appropriate credit to the original author(s) and the source, provide a link to the Creative Commons license, and indicate if changes were made.

\section{References}

Adams ES, Tschinkel WR (1995) Effects of foundress number on brood raids and queen survival in the fire ant Solenopsis invicta. Behav Ecol Sociobiol 37:233-242

AntWeb v7.42.1 (2018) http://www.antweb.org. Accessed 21 Aug 2018

Bates D et al (2018) Linear mixed-effects models using 'Eigen' and S4. R package. https://cran.r-project.org/web/packages/lme4/. Accessed 30 July 2018

Bartz SH, Hölldobler B (1982) Colony founding in Myrmecocystus mimicus Wheeler (Hymenoptera: Formicidae) and the evolution of foundress associations. Behav Ecol Sociobiol 10:137-147

Bernasconi G, Strassmann JE (1999) Cooperation among unrelated individuals: the ant foundress case. Trends Ecol Evol 14:477-482

Bolton B, Alpert G, Ward PS, Naskrecki P (2007) Bolton's Catalogue of ants of the world: 1758-2005. Harvard University Press, Cambridge (CD-ROM)

Conway JR (1980) The seasonal occurrence of sexual brood and the pre- and post-nuptial behavior of the honey ant, Myrmecocystus mexicanus Wesmael, in Colorado. N Y Entomol Soc 88:7-14

Conway JR (1983) Nest architecture and population of the honey ant, Myrmecocystus mexicanus Wesmael (Formicidae), in Colorado. Southwest Nat 28:21. https://doi.org/10.2307/3670588

Conway JR (1990) Notes on repletes, myrmecophiles, and predators of honey ant nests (Myrmecocystus mexicanus) (Hymenoptera: Formicidae) in Arizona. J N Y Entomol Soc 98:103-107

Christie M (2012) Script to calculate, output and graph allele frequencies. http://www.molecularecologist.com/wp-content/uploa ds/2012/03/Allelefrequency_calculations2.txt. Accessed 30 July 2018

Crozier RH, Pamilo P (1996) Evolution of social insect colonies: sex allocation and kin selection. Oxford University Press, New York

Fournier D, Aron S, Keller L (2004) Significant reproductive skew in the facultatively polygynous ant Pheidole pallidula. Mol Ecol 13:203-210. https://doi.org/10.1046/j.1365-294X.2003.02036.x

Fournier D, Keller L (2001) Partitioning of reproduction among queens in the Argentine ant, Linepithema humile. Anim Behav 62:10391045. https://doi.org/10.1006/anbe.2001.1848

Gadau J (2009) DNA isolation from ants. Cold Spring Harb Protoc. https://doi.org/10.1101/pdb.prot5245 
Gadau J, Fewell J (2009) Organization of insect societies: from genome to sociocomplexity. Harvard University Press, Cambridge

Gadau J, Strehl C-P, Oettler J, Holldobler B (2003) Determinants of intracolonial relatedness in Pogonomyrmex rugosus (Hymenoptera; Formicidae): mating frequency and brood raids. Mol Ecol 12:1931-1938. https://doi.org/10.1046/j.1365-294X.2003.01853 . $\mathrm{x}$

Gadau J, Gertsch PJ, Heinze J, Pamilo P, Hölldobler B (1998) Oligogyny by unrelated queens in the carpenter ant, Camponotus ligniperdus. Behav Ecol Sociobiol 44:23-33

Giraud T, Pedersen JS, Keller L (2002) Evolution of supercolonies: the Argentine ants of southern Europe. Proc Natl Acad Sci 99:6075-6079

Gotoh A, Dansho M, Dobata S et al (2017) Social structure of the polygynous ant, Crematogaster osakensis. Insectes Soc 64:123131. https://doi.org/10.1007/s00040-016-0522-y

Guénard B, Shik JZ, Booher D et al (2016) Extreme polygyny in the previously unstudied subtropical ant Temnothorax tuscaloosae with implications for the biogeographic study of the evolution of polygyny. Insectes Soc 63:543-551. https://doi.org/10.1007/ s00040-016-0498-7

Gyllenstrand N, Gertsch PJ, Pamilo P (2002) Polymorphic microsatellite DNA markers in the ant Formica exsecta. Mol Ecol Notes 2:67-69

Hagen RH, Smith DR, Rissing SW (1988) Genetic relatedness among co-foundresses of two desert ants, Veromessor pergandei and Acromyrmex versicolor (Hymenoptera: Formicidae). Psyche 95:191-201

Haney BR, Fewell JH (2018) Ecological drivers and reproductive consequences of non-kin cooperation by ant queens. Oecologia 187:643-655. https://doi.org/10.1007/s00442-018-4148-9

Heinze J, Trunzer B, Hölldobler B, Delabie JHC (2001) Reproductive skew and queen relatedness in an ant with primary polygyny. Insectes sociaux 48:149-153

Helms KR, Helms Cahan S (2012) Large-scale regional variation in cooperation and conflict among queens of the desert ant Messor pergandei. Anim Behav 84:499-507. https://doi.org/10.1016/j. anbehav.2012.05.019

Hölldobler B (1976) Tournament and slavery in a desert ant. Science 192:912-914

Hölldobler B (1981) Foraging and spatiotemporal territories in the honey ant Myrmecocystus mimicus Wheeler (Hymenoptera: Formicidae). Behav Ecol Sociobiol 9:301-314

Hölldobler B, Wilson EO (1990) The ants. Harvard University Press, Harvard

Hölldobler B, Grillenberger B, Gadau J (2011) Queen number and raiding behavior in the ant genus Myrmecocystus (Hymenoptera: Formicidae). Myrmecol News 15:53-61

Hughes WO, Boomsma JJ (2004) Genetic diversity and disease resistance in leaf-cutting ant societies. Evolution 58:1251-1260

Hughes WOH, Ratnieks FLW, Oldroyd BP (2008) Multiple paternity or multiple queens: two routes to greater intracolonial genetic diversity in the eusocial Hymenoptera. J Evol Biol 21:1090-1095. https://doi.org/10.1111/j.1420-9101.2008.01532.x

Johnson RA (2004) Colony founding by pleometrosis in the semiclaustral seed-harvester ant Pogonomyrmex californicus (Hymenoptera: Formicidae). Anim Behav 68:1189-1200. https://doi. org/10.1016/j.anbehav.2003.11.021

Jones OR, Wang J (2010) COLONY: a program for parentage and sibship inference from multilocus genotype data. Mol Ecol Resour 10:551-555

Keenan K, McGinnity P, Cross TF, Crozier WW, Prodöhl PA (2013) diveRsity: an $\mathrm{R}$ package for the estimation of population genetics parameters and their associated errors. Methods Ecol Evol 4:782-788. https://doi.org/10.1111/2041-210X.12067
Keller L, Reeve HK (1994) Genetic variability, queen number, and polyandry in social hymenoptera. Evolution 48:694. https://doi. org/10.2307/2410479

Keller L (1995) Social life: the paradox of multiple-queen colonies. Trends Ecol Evol 10:355-360

Kronauer DJ, Gadau J (2002) Isolation of polymorphic microsatellite markers in the new world honey ant Myrmecocystus mimicus. Mol Ecol Notes 2:540-541

Kronauer DJC, Hölldobler B, Gadau J (2004) Phylogenetics of the new world honey ants (genus Myrmecocystus) estimated from mitochondrial DNA sequences. Mol Phylogenet Evol 32:416-421. https://doi.org/10.1016/j.ympev.2004.03.011

Kronauer DJC, Miller DJ, Hölldobler B (2003) Genetic evidence for intra- and interspecific slavery in honey ants (genus Myrmecocystus). Proc R Soc Lond B Biol Sci 270:805-810

Kuznetsova A, Brockhoff PB, Christensen RHB (2017) lmerTest package: tests in linear mixed effects models. J Stat Softw 82:1-26. https://doi.org/10.18637/jss.v082.i13

Landi M, Queller DC, Turillazzi Strassmann SJE (2003) Low relatedness and frequent queen turnover in the stenogastrine wasp Eustenogaster fraterna favor the life insurance over the haplodiploid hypothesis for the origin of eusociality. Insectes Soc 50:262-267

Luke SG (2016) Evaluating significance in linear mixed-effects models in R. Behav Res Methods 49:1494-1502. https://doi.org/10.3758/ s13428-016-0809-y

Lynch M, Ritland K (1999) Estimation of pairwise relatedness with molecular markers. Genetics 152:1753-1766

Mattila HR, Seeley TD (2007) Genetic diversity in honey bee colonies enhances productivity and fitness. Science 317:362-364

Mintzer A, Vinson SB (1985) Cooperative colony foundation by females of the leafcutting ant Atta texana in the laboratory. J N Y Entomol Soc 1047-1051

Mintzer AC (1987) Primary polygyny in the ant Atta Texana: number and weight of females and colony foundation success in the laboratory. Insectes Soc 34:108-117

Moilanen A, Sundström L, Pedersen JS (2004) MATESOFT: a program for deducing parental genotypes and estimating mating system statistics in haplodiploid species. Mol Ecol Notes 4:795-797. https ://doi.org/10.1111/j.1471-8286.2004.00779.x

Offenberg J, Peng R, Nielsen MG (2012) Development rate and brood production in haplo- and pleometrotic colonies of Oecophylla smaragdina. Insectes Soc 59:307-311. https://doi.org/10.1007/ s00040-012-0221-2

Oldroyd BP, Fewell JH (2007) Genetic diversity promotes homeostasis in insect colonies. Trends Ecol Evol 22:408-413

Overson RP, Fewell JH, Gadau J (2011) Distribution and origin of intraspecific social variation in the California harvester ant Pogonomyrmex californicus. Insects Sociaux 63:531-541

Palmer K, Oldroyd B (2000) Evolution of multiple mating in the genus Apis. Apidologie 31:235-248

Passera L (1994) Characteristics of tramp species. In: Williams DF (ed) Exotic ants: biology, impact and control of introduced species. Westview Press, Boulder, pp 23-43

Pedersen JS, Boomsma JJ (1999) Positive association of queen number and queen-mating frequency in Myrmica ants: a challenge to the genetic-variability hypotheses. Behav Ecol Sociobiol 45:185-193

Pew J, Muir PH, Wang J, Frasier TR (2015) related: an R package for analysing pairwise relatedness from codominant molecular markers. Mol Ecol Resour 15:557-561. https://doi. org/10.1111/1755-0998.12323

Pohlert T (2014) The Pairwise Multiple Comparison of Mean Ranks Package (PMCMR). R package. http://CRAN.R-project.org/packa ge $=$ PMCMR. Accessed 30 July 2018

Qiu W, Chavarro J, Lazarus R, Rosner B, Ma J (2012) PowerSurvEpi: power and sample size calculation for survival analysis of 
epidemiological studies. R package. https://CRAN.R-project.org/ package $=$ powerSurvEpi. Accessed 30 July 2018

Queller DC, Goodnight KF (1989) Estimating relatedness using genetic markers. Evolution 43:258. https://doi.org/10.2307/2409206

R Core Team (2013) R: a language and environment for statistical computer. R Foundation for Statistical Computing, Vienna, Austria. ISBN 3-900051-07-0. http://www.R-project.org/. Accessed 18 Mar 2018

Rissing SW, Johnson RA, Pollock GB (1986) Natal nest distribution and pleometrosis in the desert leaf-cutter ant Acromyrmex versicolor (Pergande) (Hymenoptera: Formicidae). Psyche 93:177-186

Rissing SW, Pollock GB (1988) Pleometrosis and polygyny in ants. In: Jeanne RL (eds) Interindividual behavioral variability in social insects. Westview, Boulder, pp 179-222

Rosenberg MS, Anderson CD (2011) PASSaGE: pattern analysis, spatial statistics and geographic exegesis. Version 2: PASSaGE. Methods Ecol Evol 2:229-232. https://doi.org/10.1111/j.2041210X.2010.00081.X

Ross KG, Fletcher DJ (1985) Comparative study of genetic and social structure in two forms of the fire ant Solenopsis invicta (Hymenoptera: Formicidae). Behav Ecol Sociobiol 17:349-356

Satterthwaite FE (1941) Synthesis of variance. Psychometrika 6:309-316

Schindelin J, Arganda-Carreras I, Frise E et al (2012) Fiji: an opensource platform for biological-image analysis. Nat Methods 9:676-682. https://doi.org/10.1038/nmeth.2019

Schlüns EA, Wegener BJ, Schlüns H et al (2009) Breeding system, colony and population structure in the weaver ant Oecophylla smaragdina. Mol Ecol 18:156-167. https://doi.org/10.1111/ j.1365-294X.2008.04020.x

Schmid-Hempel P, Crozier RH (1999) Ployandry versus polygyny versus parasites. Philos Trans R Soc Lond B Biol Sci 354:507-515
Snelling RR (1976) A revision of the honey ants, genus Myrmecocystus (Hymenoptera: Formicidae). Nat Hist Mus Los Angeles Cty Sci Bull 24:1-166

Sommer K, Hölldobler B (1992) Pleometrosis in Lasius niger. In: Billen $\mathrm{J}$ (eds) Biology and evolution of social insects. Leuven University Press, Leuven, pp 47-50

Sommer K, Hölldobler B (1995) Colony founding by queen association and determinants of reduction in queen number in the ant Lasius niger. Anim Behav 50:287-294

Therneau $\mathrm{T}$ (2015) A package for survival analysis in S. version 2.38. $\mathrm{R}$ package. https://CRAN.R-project.org/package=survival. Accessed 30 July 2018

Therneau T, Grambsch P (2000) Modeling survival data: extending the cox model. Springer, New York (ISBN 0-387-98784-3)

Trunzer B, Heinze J, Hölldobler B (1998) Cooperative colony founding and experimental primary polygyny in the ponerine ant Pachycondyla villosa. Insectes Sociaux 45:267-276

Tschinkel WR (1992) Brood raiding in the fire ant, Solenopsis invicta (Hymenoptera: Formicidae): laboratory and field observations. Ann Entomol Soc Am 85:638-646

Tschinkel WR, Howard DF (1983) Colony founding by pleometrosis in the fire ant, Solenopsis invicta. Behav Ecol Sociobiol 12:103-113

Vásquez GM, Silverman J (2008) Intraspecific aggression and colony fusion in the Argentine ant. Anim Behav 75:583-593. https://doi. org/10.1016/j.anbehav.2007.06.019

Waloff N (1957) The effect of the number of queens of the ant Lasius flavus. (Fab.) (Hym., Formicidae) on their survival and on the rate of development of the first brood. Insectes Soc 4:391-408

Wang J (2004) Sibship reconstruction from genetic data with typing errors. Genetics 166:1963-1979

Wheeler WM (1917) The pleometrosis of Myrmecocystus. Psyche 24:180-182 